OPEN ACCESS

Edited by:

Mario Alfredo Parra,

University of Strathclyde,

United Kingdom

Reviewed by:

Antonio Giuliano Zippo,

Institute of Neuroscience, National

Research Council (CNR), Italy

Carlos Jesus Toro-Huamanchumo,

Universidad San Ignacio de Loyola, Peru

*Correspondence:

Patricia J. García

patricia.garcia@upch.pe

Specialty section:

This article was submitted to Dementia and Neurodegenerative

Diseases,

a section of the journa

Frontiers in Neurology

Received: 14 November 2020

Accepted: 21 April 2021

Published: 17 June 2021

Citation:

Diaz MM, Zacarías MG, Sotolongo $P$, Sanes MF, Franklin DJ, Marquine MJ,

Cherner M, Cárcamo C, Ellis RJ,

Lanata S and García PJ (2021)

Characterization of HIV-Associated

Neurocognitive Impairment in Middle-Aged and Older Persons With

HIV in Lima, Peru.

Front. Neurol. 12:629257.

doi: 10.3389/fneur.2021.629257

\section{Characterization of HIV-Associated Neurocognitive Impairment in Middle-Aged and Older Persons With HIV in Lima, Peru}

\author{
Monica M. Diaz ${ }^{1,2,3}$, Marcela Gil Zacarías ${ }^{4}$, Patricia Sotolongo ${ }^{5}$, María F. Sanes ${ }^{4}$, \\ Donald J. Franklin ${ }^{6,7}$, María J. Marquine ${ }^{6,7}$, Mariana Cherner ${ }^{6,7}$, Cesar Cárcamo ${ }^{3}$, \\ Ronald J. Ellis ${ }^{6,8}$, Serggio Lanata ${ }^{9,10}$ and Patricia J. García ${ }^{3,11 *}$
}

${ }^{1}$ Department of Medicine, University of California, San Diego, San Diego, CA, United States, ${ }^{2}$ University of California Global Health Institute, San Diego, CA, United States, ${ }^{3}$ Facultad de Salud Pública, Universidad Peruana Cayetano Heredia, Lima, Peru, ${ }^{4}$ Facultad de Medicina Alberto Hurtado, Universidad Peruana Cayetano Heredia, Lima, Peru, ${ }^{5}$ Department of Psychology, Jackson Memorial Hospital, Miami, FL, United States, ${ }^{6}$ Human Immunodeficiency Virus (HIV) Neurobehavioral Research Center, University of California, San Diego, San Diego, CA, United States, ${ }^{7}$ Department of Psychiatry, University of California, San Diego, San Diego, CA, United States, ${ }^{8}$ Department of Neurosciences, University of California, San Diego, San Diego, CA, United States, ${ }^{9}$ Weill Institute for Neurosciences, Memory and Aging Center, University of California, San Francisco, San Francisco, CA, United States, ${ }^{10}$ Global Brain Health Institute, University of California, San Francisco, San Francisco, CA, United States, ${ }^{11}$ School of Public Health, University of Washington, Seattle, WA, United States

Background: With widespread use of antiretroviral medications, people living with HIV $(\mathrm{PWH})$ are living longer worldwide, increasing their risk of developing neurocognitive impairment $(\mathrm{NCl})$. The proportion of Peruvians over age 60 is expected to increase to $25 \%$ of the population by 2050 , including $\mathrm{PWH}$. Therefore, the problem of aging and $\mathrm{NCl}$, especially in the setting of HIV infection, is uniquely pressing. We sought to study the rates of and risk factors associated with $\mathrm{NCl}$ among middle-aged and older $\mathrm{PWH}$ in Lima, Peru.

Materials and Methods: Sociodemographic, medical (infectious and non-infectious), and psychiatric comorbidity and laboratory data were collected. We administered a brief neuropsychological battery evaluating seven cognitive domains affected in HIV-associated $\mathrm{NCl}$ and a depression screening. Cognitive test raw scores were converted to $T$-scores that were demographically adjusted. Descriptive statistics were performed together with regression (unadjusted and adjusted) analyses to determine potential risk factors for $\mathrm{NCl}$ among $\mathrm{PWH}$.

Results: This was a cross-sectional study in which $144 \mathrm{PWH}$ aged $\geq 40$ years attending a large HIV clinic in Lima, Peru, were recruited from September 2019 to March 2020. Mean age was $51.6 \pm 7.7$ years, and mean years of education were $14.0 \pm 3.1$ with $15 \%$ females. Median [interquartile range (IQR)] current CD4 and nadir CD4 were 554 (371, $723)$ and $179(83,291)$, respectively, and $10 \%$ currently had AIDS. The prevalence of $\mathrm{NCI}$ was $28.5 \%$, and many demonstrated difficulty with attention and working memory (70\%). One-quarter of PWH had mild depression or worse on Patient Health Questionnaire 9 (PHQ-9 $\geq 5$ ). In bivariate analyses, neither a depression history nor a higher PHQ-9 score correlated with $\mathrm{NCl}$. No other non-communicable medical or psychiatric comorbidity nor HIV characteristic was predictive of $\mathrm{NCl}$. Having a positive lifetime history of hepatitis 
B infection, pulmonary tuberculosis, or syphilis increased risk of $\mathrm{NCl}(\mathrm{PR} 1.72 ; 95 \% \mathrm{Cl}$ 1.04-2.86) in unadjusted analyses, but not in adjusted analyses.

Conclusions: $\mathrm{NCl}$ among older Peruvians with HIV was found to be highly prevalent with levels consistent with prior reports of $\mathrm{HIV}$-associated $\mathrm{NCI}$ worldwide. Common latent HIV-associated co-infections, including latent syphilis, hepatitis B infection, or pulmonary tuberculosis, may increase the risk of $\mathrm{NCl}$ among middle-aged and older $\mathrm{PWH}$ in Peru.

Keywords: HIV-associated neurocognitive disorder (HAND), HIV/AIDS \& infectious diseases, cognitive impairment, dementia, Latin America, Peru, non-communicable disease

\section{INTRODUCTION}

The number of people living with dementia of any cause worldwide in 2015 was estimated at 48 million people, and this figure is expected to rise to 135 million by 2050 , with $63 \%$ of cases living in low- and middle-income countries (LMICs) (1). With increased access and use of antiretroviral therapy (ART), the life expectancy of people living with HIV (PWH) has markedly increased $(2,3)$. This represents a breakthrough in the field but also a new challenge due to the increasing prevalence of non-communicable comorbidities, such as diabetes mellitus and hyperlipidemia, associated with aging with HIV including various forms of neurocognitive impairment (NCI) $(4,5)$. In addition, our understanding of risk factors for NCI has evolved over time during the ART era, with more chronic comorbidities thought to worsen NCI as PWH live longer (6-8). HIV-associated neurocognitive disorder (HAND) is the most common form of $\mathrm{NCI}$ among PWH. It presents with varying degrees of neurologic dysfunction (9) and is associated with increased morbidity and mortality $(3,7,10)$. Since the introduction of ART, the incidence of HIV-associated dementia, a severe form of HAND, has decreased $(11,12)$, but the overall prevalence of HAND worldwide remains stable $(7,8)$. Peru is a country of 32 million people that is undergoing rapid aging. Currently, 3.3 million people are over the age of 60 (13), and it is estimated that by 2050, $25 \%$ of the Peruvian population will be over age 60 (1). Therefore, the problem of aging and $\mathrm{NCI}$ is uniquely pressing among PWH.

Several studies have reported that the prevalence of HAND in North America and in some European countries exceeds 30\% and affects more than $50 \%$ of people with Acquired Immune Deficiency Syndrome (AIDS) $(7,8,14,15)$. There is a paucity of research on the prevalence and characterization of HAND in Latin America. Published studies have reported the prevalence of mild neurocognitive disorder, a milder symptomatic form of $\mathrm{NCI}$, in $\mathrm{PWH}$ at $20 \%$, and $\sim 50 \%$ have asymptomatic NCI without functional impairment $(16,17)$. In Peru in particular, there are limited studies addressing NCI among PWH with no studies specifically on middle-aged to older PWH $(18,19)$. Moreover, there are no standard cognitive screening protocols nor clinical management guidelines for $\mathrm{PWH}$ with NCI despite 70,000 PWH living in Peru, with 60\% currently having access to $\operatorname{ART}(20,21)$. Cognitive decline in the general population presents significant medical, social, and economic challenges (22), and Peruvian health systems, like those of many Latin American countries, will face challenges with the increasing burden of NCI (1). Documenting the prevalence of HAND and associated risk factors among Peruvians with HIV is the first step in identifying the burden of this disease, which may lead to implementation of public policies that can help PWH living with NCI to improve their quality of life. In this study, we sought to study rates of HIV-related NCI in a group of older Peruvians with HIV living in Lima and determine the risk factors for NCI among PWH.

\section{MATERIALS AND METHODS}

This was a cross-sectional study of PWH living in Lima, Peru, in which demographic data were collected and clinical and neurocognitive evaluations were performed. This study was conducted from September 2019 until March 2020. Participants were men and women aged 40 years or older, Peruvian-born, and native Spanish speakers recruited from a large HIV clinic run by a non-governmental organization. All $\mathrm{PWH}$ enrolled had a record of a positive ELISA and Western blot tests in their medical chart and had been receiving ART therapy for at least 1 month at the outpatient clinic. All participants had completed at least 6 years of schooling (primary school) and had the ability and willingness to participate in the study and provide informed consent. Individuals with a self-reported history of non-HIV-related neuromedical comorbidities that may cause NCI were excluded by administering to potential participants a screening questionnaire prior to their enrollment. This screening questionnaire included questions about any known non-HIVrelated neurological disorder that led to cognitive impairment (e.g., epilepsy or stroke), psychotic disorders (schizophrenia or bipolar disorder), and brain injury with loss of consciousness for more than $30 \mathrm{~min}$ without return to premorbid baseline. Those with a current and lifetime substance use disorder according to the Diagnostic and Statistical Manual of Mental Disorders-5 (DSM-5) were excluded.

\section{Study Procedures}

Eligible patients attending the HIV clinic were identified by study personnel the day prior to their visit if they met the age criteria for enrollment. Nurses and physicians invited these potentially eligible patients to enroll in the study. With the patient's verbal consent, study personnel then contacted the patients by phone and invited them to the clinic for a scheduled study visit. At the study visit, all study procedures were explained to the participant with ample time to answer any questions, and written 
informed consent was obtained. Patients were then interviewed and examined by a neurologist (MMD) or a physician research assistant with training in neurological examination and were supervised by the neurologist. Sociodemographic information including age, sex, years of education achieved, occupation, place of birth, and place of current residence was collected. Self-reported past medical history, including history of prior infections [opportunistic (in PWH only) and non-opportunistic] and chronic non-communicable diseases, was also collected and was corroborated with review of the medical chart following the participant's study visit. We also administered an ART adherence questionnaire to all participants. All participants underwent a comprehensive neuromedical assessment including a complete neurological exam. Following the physical examination, a neurocognitive battery was administered to evaluate neurocognitive function, the Pfeffer Activities of Daily Living questionnaire (PFAQ) to determine functional status, and the Patient Health Questionnaire (PHQ)-9 to screen for depression (Section Instruments Utilized).

We obtained the following information from the medical chart: prior and current ART regimens, any adverse events related to ART, corroboration of self-reported past medical history with physician's clinic assessments in the chart. Laboratory data obtained from chart review included any lifetime positive rapid plasma reagin (RPR) test, herpes simplex virus (HSV)-1 antibody test, tuberculosis (TB) sputum test, and hepatitis B surface antigen ( $\mathrm{HbsAg}$ ) test results. We also noted the most recent hemoglobin, creatinine, total cholesterol, and triglyceride levels.

Following the study visit, the results of the neurocognitive battery were normed as described below, and participants and their treating physician were given a summary of their test results. We provided participants with recommendations on healthy living strategies and strategies for prevention of cognitive decline (23). For those in whom NCI was detected, a neurologist (MMD) counseled the participant by phone or in-person visit on their results and NCI prevention strategies, and results were discussed with the treating physician.

\section{Instruments Utilized}

\section{Neuropsychological Test Battery}

The neuropsychological test battery evaluated seven cognitive domains [abstraction/executive function, motor performance, memory (learning and recall), attention/working memory, verbal fluency/language, speed of information processing, and visuospatial orientation] that are commonly affected in HIVassociated NCI and that have been widely utilized to assess HIVassociated NCI in the United States, in Europe (9, 24, 25), and in Brazil (26). The domains were evaluated using the following tests:

- Abstraction and executive function: Color Trails Test 2 (27);

- Motor performance: Grooved Pegboard (dominant hand) and Grooved Pegboard (non-dominant hand) (28);

- Memory (learning and recall): Hopkins Verbal Learning TestRevised (HVLT-R)-Total Learning, HVLT-R Delayed Recall (29), and Benson Figure Recall (30);
- Attention and working memory: Weschler Adult Intelligence Scale (WAIS)-3 Digit Span (31);

- Verbal and language fluency: semantic/category fluency (Animal Naming) and letter fluency (PMR) (32);

- Speed of information processing: Color Trails Test 1 (33); and - Visuospatial orientation: Benson Figure immediate copy (34).

The instruments have been translated, and most have been validated into Spanish by native Spanish speakers and used in several other studies for Spanish speakers in Latin America (35-37). Raw test scores were converted into demographically adjusted $T$-scores (adjusted for age, sex, and education level) for each test. Norms for native Spanish speakers from the Neuropsychological Norms for the US-Mexico Border Region in Spanish (NP-NUMBRS) were applied to all tests when available, including for semantic/category fluency (Animal Naming) (38), letter fluency (PMR) (38), HVLT-R Total Learning and Delayed Recall (39), and Grooved Pegboard (dominant and nondominant hand) (40). English-speaking norms with similar mean educational levels to that of our study were utilized for those tests for which there were no demographically adjusted Spanish NP-NUMBRS norms available given there are no Spanishspeaker norms for a Peruvian population that were adequate for our population.

Normed $T$-scores were computed for each test, with regression-based adjustments for the effects of age, sex, and educational level. For each test, $T$-scores were converted to deficit scores as follows: $T>39$ (no worse than -1 standard deviation) was considered normal and assigned a deficit score of 0 . T-scores below 40 were converted to deficit scores as follows: $35-39=1$ (mild impairment); 30-34=2 (mild to moderate impairment); 25-29 = 3 (moderate impairment); 20 $24=4$ (moderate to severe impairment); and $T<20=5$ (severe impairment). For each domain, an average of the $T$-scores for each test comprising each domain were computed, and this generated a mean $T$-score for each domain. Deficit scores were summed across the test battery and then divided by the total number of individual measures to compute the Global Deficit Score (GDS), a measure of global cognitive impairment. The GDS summarizes the number and severity of neurocognitive deficits across the entire test battery. A GDS cutoff of $\geq 0.50$ was used to determine global NCI $(7,41,42)$.

\section{Pfeffer Activities of Daily Living Questionnaire (PFAQ)}

Subjective cognitive difficulties were assessed using the validated Spanish version of PFAQ (43-45). In the PFAQ, participants rate themselves as having or not having cognitive difficulties in their daily lives on a 4-point scale, in domains of memory, language and communication, sensory perception, motor skills, and higher-level cognitive functions. The score used is the sum of items on which the participants reported experiencing difficulties ranging from normal ( 0 ) to dependent (3), for a total of 30 points, with higher scores indicating worse functional status (43). When a caregiver or companion was present during the interview, the questionnaire was corroborated with the caregivers' report with the participants' permission. Employment status was derived from the demographic interview, which collected information on 
whether the participant was working and the type of employment (Supplementary Material 1).

\section{PHQ-9 for Depression Screening}

This is a nine-item questionnaire designed to screen for depression in primary care and other medical settings was administered to all participants as a depression screening measure (46-48). The PHQ-9 scores each of the nine DSMIV criteria for depression as " 0 " (not at all) to " 3 " (nearly every day), addressing somatic (fatigue, appetite, and sleep quality) and non-somatic (suicidal ideation and feelings of guilt) depressive symptoms; higher scores indicate worse depressive symptomatology. The standard cutoff score to identify major depression is 10 or above (46-48). The PHQ-9 has been previously validated in Spanish for use in Peru (49), has been used in other Spanish-speaking populations throughout Latin America and Spain (50-52), and has been validated for use in depression screening in HIV in South Africa (53) (Supplementary Material 2).

\section{NCI (or HAND) Diagnosis for PWH}

Global cognitive impairment was defined as a GDS score $\geq 0.5$, and individual domain cognitive impairment was defined as a domain-averaged T-score $<40$. HIV-associated NCI diagnoses were assigned according to the Frascati criteria (9). To receive a diagnosis of HIV-associated dementia, participants had to have moderate to severe impairment on neuropsychological testing and require major assistance in activities of daily living based on the PFAQ. Mild neurocognitive disorder was diagnosed when NCI was mild to moderate on neuropsychological testing by GDS score, and difficulties were reported in two Pfeffer areas except that for participants with at least moderate depressive symptomatology on the PHQ-9; three areas were required on the Pfeffer questionnaire. Asymptomatic NCI was defined as mild to moderate impairment without any functional impairment on the Pfeffer questionnaire.

\section{Statistical Analyses}

Descriptive statistics were computed with means [standard deviations (SDs)] or medians [interquartile ranges (IQRs)] for all demographic and HIV characteristic continuous variables. Frequencies and percentages were computed for past medical and psychiatric history variables, and to determine the frequency of depressive symptoms, functional dependence and cognitive impairment were used based on defined cutoff points for each test. Univariable (without adjustment for covariates) and multivariable (adjusted for relevant covariates) regression analyses were performed using GLM with link log and family Poisson to obtain unadjusted and adjusted prevalence ratios (PR and aPR, respectively). All covariates [age $\geq 50$ years, female sex, educational level of secondary school or less, comorbid conditions (hypertension, hyperlipidemia, anemia, self-reported depression, $\mathrm{PHQ}-9$ score $\geq 5$, self-reported anxiety, past hepatitis B infection, past TB infection, and past syphilis infection)], current absolute CD4 count $<500$, nadir CD4 count 51-200, nadir CD4 count $<50$, detectable plasma viral load, and HIV duration $\geq 5$ years) with a $p<0.10$ in univariable analyses were included as covariates in the multivariable analyses. A $p<0.05$ was considered statistically significant. All statistical analyses were performed using the JMP Pro ${ }^{\circledR}$ statistical software, version 14.2.0 (SAS Institute Inc., Cary, NC, USA) and STATA (College Station, TX, USA).

\section{Ethical and Institutional Review Board Approvals}

The study and instruments were approved by the institutional review boards of Universidad Peruana Cayetano Heredia (Lima, Peru) and Via Libre (Lima, Peru). The institutional review board of the University of California, San Diego (San Diego, CA, USA), exempted the study from review. Written informed consent was obtained from study participants once the research procedure was explained to them, and sufficient time was given for participants to have any questions answered. Participants were not reimbursed for their time.

\section{RESULTS}

\section{Demographics and Medical Characteristics}

We recruited $144 \mathrm{PWH}$ with a mean age of $51.6 \pm 7.7$ years and mean years of education of $14.0 \pm 3.1$ ( $15.2 \%$ females). We found that $2 / 144(1.4 \%)$ have completed up to primary school, $48 / 144$ (33.3\%) have completed up to secondary school, 76/144 (52.8\%) have had some or completed university or technical school, and $18 / 144(12.5 \%)$ have completed a post-graduate degree (data not shown). We found that a small proportion of $\mathrm{PWH}$ were unemployed (13.0\%) (Table 1).

Non-communicable comorbidities were common. Less than one third had dyslipidemia (32.6\%), 13.7\% had hypertension, and very few had diabetes $(5 \%)$, anemia $(10 \%)$, or lifetime seizure history $(4.3 \%)$ (Table 1). The most recent mean hemoglobin reported in laboratory analyses was a mean (SD) of 13.9 (1.52), and mean creatinine levels were within the normal range [0.93 (0.17)]. Recent mean total cholesterol levels were 196.2 (46.0), and triglycerides were 170.7 (98.1) (Table 2). Alcohol use was more common among $\mathrm{PWH}(47 \%)$, but current cigarette smoking (16.7\%), marijuana use (2.8\%), and cocaine use $(1.4 \%)$ were less common (Table 1). Self-reported past infectious history (corroborated with chart review) was obtained. Past history of pulmonary TB (15.2\%), HSV infection (30.9\%), and syphilis (29.5\%) was common. All participants with a positive TB history completed treatment, and nearly all who had a history of syphilis per self-report completed treatment $(97.2 \%$ of those with a syphilis history). Of those participants who had an RPR test in the medical chart, $28 / 105(26.7 \%)$ had a positive RPR test in the past. Of 92 participants, eight $(8.7 \%)$ had a positive lifetime TB sputum test (Table 2). Prior hepatitis infection was common among PWH with more than one third (35.7\%) having had any hepatitis infection in the past (hepatitis A $18.1 \%$, hepatitis B $16.7 \%$, and hepatitis C 1.4\%) (Table 1). Of those who had an HBsAg test available in their medical chart, 11/100 (11\%) had a positive HBsAg. There were five cases of a prior central nervous system (CNS) infection by self-report, including CNS amoebiasis, 
TABLE 1 | Demographic and medical characteristics $(N=144)$.

Median [IQR], Mean (SD), or n (\%)

\begin{tabular}{|c|c|}
\hline \multicolumn{2}{|l|}{ Demographic variables } \\
\hline Age & $51.6(7.7)$ \\
\hline Sex ( $n, \%$ females) & $22(15.2 \%)$ \\
\hline Education (years) & $14.0(3.1)$ \\
\hline Unemployed or retired & $18(13.0 \%)$ \\
\hline \multicolumn{2}{|c|}{ Past non-infectious medical or psychiatric history ${ }^{a}$} \\
\hline Hypertension & $19(13.7 \%)$ \\
\hline Hyperlipidemia & $46(32.6 \%)$ \\
\hline Diabetes or prediabetes & $7(5 \%)$ \\
\hline Anemia & $14(10 \%)$ \\
\hline Seizure (ever) & $6(4.3 \%)$ \\
\hline Depression (by self-report) & $21(15.2 \%)$ \\
\hline PHQ-9 total score & $3.34(4.10)$ \\
\hline Depression $(P H Q-9>4)$ & $35(25.2 \%)$ \\
\hline Anxiety (by self-report) & 15 (10.9\%) \\
\hline \multicolumn{2}{|c|}{ Past infectious medical history ${ }^{a}$} \\
\hline Pulmonary TB & $21(15.2 \%)$ \\
\hline Completed TB treatment & $21(100 \%)$ \\
\hline Herpes simplex virus & $43(30.9 \%)$ \\
\hline Syphilis & $41(29.5 \%)$ \\
\hline Completed syphilis treatment & $35 / 37(97.2 \%)$ \\
\hline Any hepatitis type & $50(35.7 \%)$ \\
\hline Hepatitis A & $26(18.1 \%)$ \\
\hline Hepatitis B & $24(16.7 \%)$ \\
\hline Hepatitis C & $2(1.4 \%)$ \\
\hline CNS infection & $5(3.6 \%)$ \\
\hline CNS amoebiasis & $1(20 \%)$ \\
\hline Cryptococcal meningitis & $1(20 \%)$ \\
\hline Herpes encephalitis & $1(20 \%)$ \\
\hline Neurocysticercosis & $1(20 \%)$ \\
\hline CNS toxoplasmosis & $1(20 \%)$ \\
\hline \multicolumn{2}{|l|}{ Current substance use $^{a}$} \\
\hline Alcohol use & $68(47 \%)$ \\
\hline Cigarette smoking & $24(16.7 \%)$ \\
\hline Marijuana use & $4(2.8 \%)$ \\
\hline Cocaine use & 2 (1.4\%) \\
\hline
\end{tabular}

aby self-report and corroboration with medical chart whenever possible.

$I Q R$, interquartile range; $S D$, standard deviation; TB, tuberculosis.

cryptococcal meningitis, HSV encephalitis, neurocysticercosis, and CNS toxoplasmosis reported (Table 1).

\section{HIV Characteristics}

PWH had a mean duration of HIV infection of $9.9 \pm 7.1$ years, and all participants were currently on ART. On the antiretroviral adherence questionnaire, the large majority of PWH [116/138 (84.1\%)] never missed a dose in the past month, and $17 / 138$ $(12.3 \%)$ missed one to three doses in the past month, and $5 / 138(3.6 \%)$ missed more than three doses in the past month. PWH had well-controlled HIV infection with a median absolute CD4 count of 554 cells $/ \mathrm{mm}^{3}$ (IQR: $372-732$ ) and a nadir CD4 count of 179 cells $/ \mathrm{mm}^{3}$ (IQR: $83-291$ ). A detectable plasma viral
TABLE 2 | HIV characteristics and laboratory results $(N=144)$.

Median [IQR], Mean (SD), or $\mathrm{n}(\%)$

$\begin{array}{lc}\text { HIV characteristics } & \\ \text { Current CD4 } & 554[372-723] \\ \text { Nadir CD4 } & \\ \text { AIDS history } & 179[83-261] \\ \text { HIV infection duration (years) } & \\ \text { On antiretrovirals } & 9.9(7.1) \\ \text { Detectable plasma viral load (>50 copies/mL) } & 144(100 \%) \\ & 18 / 126(14.3 \%)\end{array}$

Detectable plasma viral load (>50 copies $/ \mathrm{mL}) \quad 18 / 126(14.3 \%)$

Current antiretroviral use $(n=131)$

Nucleoside reverse transcriptase inhibitor (NRTI)

Lamivudine (3TC) $\quad 80(61.1 \%)$

Tenofovir (TDF) $\quad 80(61.1 \%)$

Emtricitabine (FTC) $\quad 45(34.4 \%)$

Zidovudine (AZT) $\quad 36(27.5 \%)$

Abacavir (ABC) $12(9.2 \%)$

Stavudine (D4T) $1(0.7 \%)$

Didanosine $0(0 \%)$

Non-nucleoside reverse transcriptase inhibitors (NNRTI)

Efavirenz (EFV)

$91(69.5 \%)$

Nevirapine (NVP)

$15(11.5 \%)$

Protease inhibitor

Lopinavir/ritonavir (Lop/r) $10(7.6 \%)$

Atazanavir (ATZ)/ritonavir $\quad 7(5.3 \%)$

Darunavir 2 (1.5\%)

Integrase inhibitor

Raltegravir $\quad 1(0.8 \%)$

Dolutegravir $1(0.8 \%)$

Laboratory analyses (most recent)

Hemoglobin

$13.9(1.52)$

Creatinine

$0.93(0.17)$

Total cholesterol $196.2(46.0)$

Triglycerides 170.7 (98.1)

Positive RPR (ever) 28/105 (26.7\%)

Hepatitis B surface antigen (ever) $\quad 11 / 100(11 \%)$

Positive TB sputum test (ever) 8/92 (8.7\%)

Any latent HIV coinfection ${ }^{c} \quad$ 45/144 (31.3\%)

${ }^{a}$ of 128 participants; bof 120 participants; 'chepatitis B, tuberculosis, or syphilis prior infections.

$I Q R$, interquartile range; $S D$, standard deviation.

load $\left(>50,000\right.$ copies $/ \mathrm{mm}^{3}$ ) was noted in $14.3 \%$ of PWH. The most common non-nucleoside reverse transcriptase inhibitor (NRTI) in current use by the participants were lamivudine [3TC, 80/131 (61.1\%)] and tenofovir [TDF, 80/131 (61.1\%)]. Of the non-NRTIs, efavirenz was common [91/131 (69.5\%)]. Protease inhibitors and integrase inhibitors were rarely used (Table 2 ).

\section{Depression and Functional Assessment Screening Results}

Of the self-reported psychiatric history, $15.2 \%$ of participants self-reported a current depression diagnosis and $10.9 \%$ selfreported anxiety. Depression on the PHQ-9 depression screening 


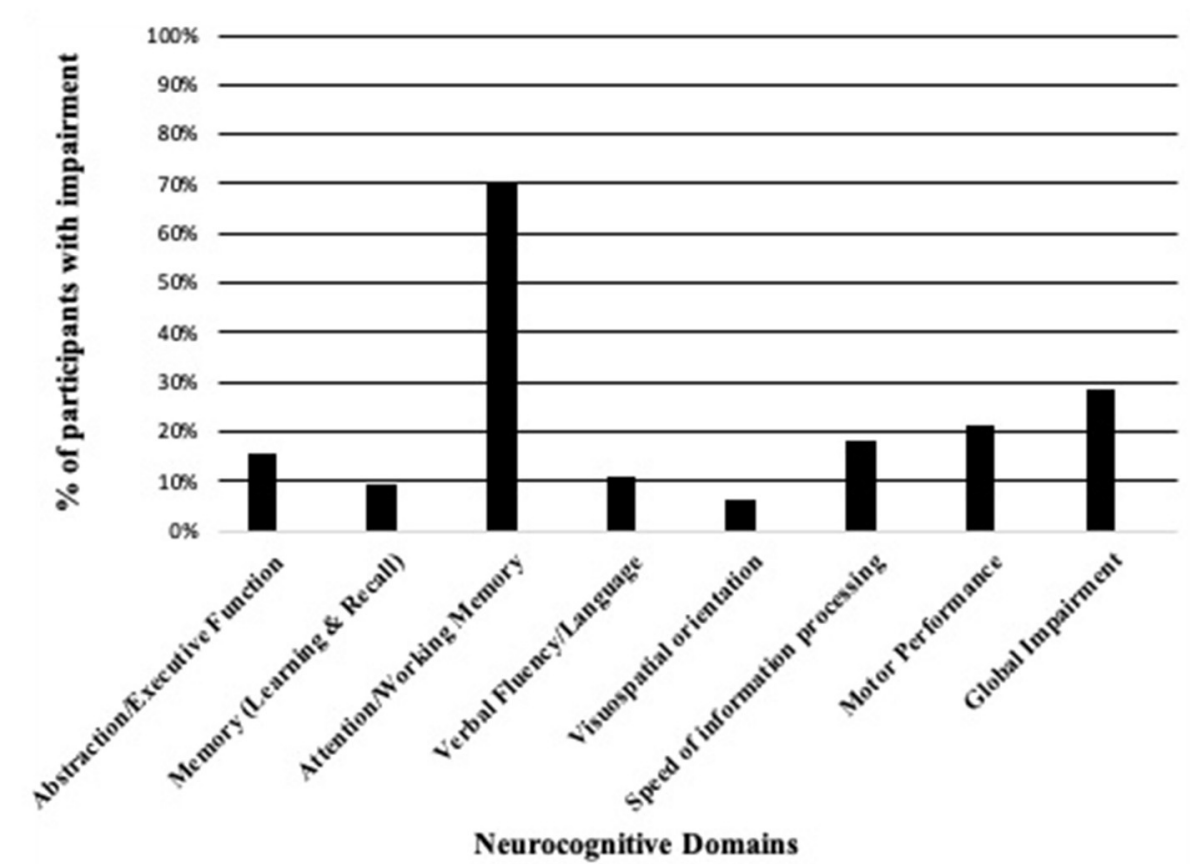

FIGURE 1 | Neurocognitive domain impairment among PWH ( $N=144)$.

(defined as PHQ-9 score $\geq 5$ ) was common, with one quarter of participants screening positive for depression (Table 1). To assess functional status, a PFAQ cutoff of $\geq 9$ was used, and we found that there were no participants that met criteria for functional dependence. When the cutoff was set lower (PFAQ total score $\geq 4$ ), we found that very few had difficulty with independent activities of daily living (2.8\%). In unadjusted regression analyses, only self-reported anxiety was a risk factor for depression on PHQ-9 [PR 2.03 (1.08-3.82); $p=0.047]$, but no other demographic, past medical history, or HIV characteristic variable posed an increased risk on depression by PHQ-9 score (data not shown).

\section{Neurocognitive Testing Results}

We found that nearly $30 \%$ of participants had global NCI and that all participants with global NCI had asymptomatic NCI with no participants having mild neurocognitive disorder or HIV-associated dementia. We found high rates of impairment in the attention and working memory domain (69.9\%) and that nearly one fifth of PWH (18.1\%) had difficulty with speed of information processing (Figure 1, Table 3). In unadjusted regression models, HIV infection did not increase risk of NCI [PR $0.99(0.60-1.63)]$, but any latent HIV coinfection (including past history of hepatitis B infection, $\mathrm{TB}$ infection, or syphilis) increased the risk of NCI [PR $1.72(1.04-2.86)]$, and a current CD4 absolute count of $<500$ cells $/ \mathrm{mm}^{3}$ approached statistical significance [PR 1.64 (0.96-2.8)]. Neither was a statistically significant risk factor associated with NCI in adjusted models [aPR 1.55 (0.81-2.92) for latent coinfection and aPR 1.64 (0.87-3.10) for absolute CD4 count $<500$ cells] (Table 4). In a sub-analysis of PWH (not shown) with an undetectable plasma viral load only ( $n$ $=126$ ), we found that $28.6 \%$ of PWH had NCI, and in the unadjusted regression analyses, the PR of HIV positivity on NCI remained unchanged.

\section{DISCUSSION}

In this study, we characterized NCI rates among middle-aged and older PWH living in Lima, Peru, and risk factors for NCI in this population. We found that nearly $30 \%$ of $\mathrm{PWH}$ had asymptomatic NCI and that no PWH had symptomatic NCI with functional impairment. Among PWH, a risk factor for NCI that was identified was having had a history of latent coinfection, but this was no longer statistically significant in adjusted analyses. Our findings are comparable to previously published findings with comparable NCI rates worldwide.

Several studies have assessed NCI and dementia in geriatric populations in Peru, but none have focused on an older Peruvian population with HIV. In Latin America, eight publications have described HAND prevalence and associated risk factors among PWH aged $\geq 40$ years [seven from Brazil $(16,54-60)$ one from Mexico (61)], with none from Peru. These studies utilized different neurocognitive screening tools, including the International HIV Dementia Scale (IHDS) (16, 56-58) with HAND prevalence ranging from 37 to $64 \%$ using this scale or the Mini Mental State Exam (MMSE) (62) with prevalence ranging from 27 to $37 \%$. $(54,59)$ Several studies from Brazil reported NCI prevalence specifically among an older age group 
TABLE 3 | Neurocognitive and functional status screening results of PWH $(N=$ 144).

Median [IQR], Mean (SD), or n (\%)

\begin{tabular}{|c|c|}
\hline \multicolumn{2}{|l|}{ Functional status screening (PFAQ) } \\
\hline PFAQ total score & $0.46(1.10)$ \\
\hline Functionally dependent (PFAQ $\geq 9)$ & $0(0 \%)$ \\
\hline Some difficulty with IADLs (PFAQ $\geq 4)$ & $4(2.8 \%)$ \\
\hline \multicolumn{2}{|c|}{ Neurocognitive test results by cognitive domain ( $\%$ cognitively impaired) } \\
\hline Abstraction and executive function & $22(15.3 \%)$ \\
\hline Memory (learning and recall) & $13(9.4 \%)$ \\
\hline Attention and working memory & $100(69.9 \%)$ \\
\hline Verbal fluency and language & $15(10.5 \%)$ \\
\hline Visuospatial orientation & $9(6.3 \%)$ \\
\hline Speed of information processing & $26(18.1 \%)$ \\
\hline Motor & $30(21.0 \%)$ \\
\hline Global impairment* & $41(28.5 \%)$ \\
\hline Asymptomatic neurocognitive impairment & $41(100 \%)$ \\
\hline Mild neurocognitive disorder & $0(0 \%)$ \\
\hline HIV-associated dementia & $0(0 \%)$ \\
\hline \multicolumn{2}{|c|}{$\begin{array}{l}\text { Neurocognitive test results by cognitive domain } \\
\text { (demographically adjusted T-score, mean } \pm S D \text { ) }\end{array}$} \\
\hline Abstraction and executive function & $50.9(13.8)$ \\
\hline Memory (learning and recall) & $50.1(7.9)$ \\
\hline Attention and working memory & $36.5(7.6)$ \\
\hline Verbal fluency and language & $53.6(11.4)$ \\
\hline Visuospatial orientation & $51.3(7.0)$ \\
\hline Speed of information processing & $48.6(14.2)$ \\
\hline Motor & $47.3(8.8)$ \\
\hline GDS & $0.42(0.43)$ \\
\hline
\end{tabular}

${ }^{*}$ Global impairment considered a GDS of $\geq 0.5$.

$I A D L$, independent activities of daily living; IQR, interquartile range; PFAQ, Pfeffer Functional Assessment Questionnaire; SD, standard deviation.

of $\mathrm{PWH}$ aged $\geq 50$ years with prevalence ranging from 23 to $54 \%$, $(16,54,57,59)$ and in Mexico, a higher prevalence of HAND (66\%) among PWH aged $\geq 50$ years was associated with prefrailty (61). Notably, few studies reported on asymptomatic NCI without impairment in functional status. Among Brazilian PWH with mean age of $42.5 \pm 9.1$ years, asymptomatic NCI rates were higher than those found in our study $(48.3 \%$ in the Brazilian study vs. $28.5 \%$ in our study) $(26,63)$. Despite these assessments of HAND from some Latin American countries, prevalence differs depending on the geographic population surveyed and the NCI screening tool utilized and the clinical and demographic characteristics of the group, including immunosuppression, viral suppression, comorbidities, and age.

Only two studies to date have investigated NCI in HIV in Peru. One study utilized a subjective memory complaint questionnaire to determine its utility in identifying NCI in PWH in Peru; however, this sample consisted of PWH who were younger than that of our group (mean age 34.3 years) with a high proportion of alcohol use disorder (41\%) and depression (42.5\%) (18). Unlike in our study, this study did not assess NCI using objective standardized neurocognitive tests, limiting its utility in objective
TABLE 4 | Regression models (unadjusted and adjusted) for risk factors for neurocognitive impairment $(N=144)$.

\begin{tabular}{|c|c|c|}
\hline \multirow[b]{2}{*}{ Variable } & \multicolumn{2}{|c|}{$\begin{array}{l}\text { Global neurocognitive impairment }{ }^{\star *} \\
\text { Yes, } n=41(28.5 \%)\end{array}$} \\
\hline & $\begin{array}{l}\text { Unadjusted } \\
\text { Prevalence Ratio } \\
(95 \% \mathrm{Cl})\end{array}$ & $\begin{array}{l}\text { Adjusted } \\
\text { Prevalence Ratio } \\
(95 \% \mathrm{Cl})\end{array}$ \\
\hline$\geq$ Age 50 years & $1.27(0.74-2.19)$ & - \\
\hline Female sex & $1.14(0.58-2.24)$ & - \\
\hline $\begin{array}{l}\text { Educational level, secondary } \\
\text { school or less }\end{array}$ & $1.21(0.72-2.03)$ & - \\
\hline Hypertension & $0.88(0.40-1.95)$ & - \\
\hline Hyperlipidemia & $0.85(0.48-1.52)$ & - \\
\hline Anemia & $1.24(0.59-2.64)$ & - \\
\hline Depression (self-report) & $1.62(0.91-2.89)$ & - \\
\hline Depression (PHQ-9 $\geq 5$ ) & $1.54(0.92-2.59)$ & - \\
\hline Anxiety (self-report) & $0.91(0.38-2.20)$ & - \\
\hline $\begin{array}{l}\text { Current absolute CD4 } \\
\text { count }<500 \text { (cells/mm³) }\end{array}$ & $1.64(0.96-2.8)^{\star}$ & $1.64(0.87-3.10)$ \\
\hline Nadir CD4 51-200 (cells/mm³) & $1.13(0.64-1.99)$ & - \\
\hline Nadir CD4 <50 (cells/mm³) & $1.68(0.91-3.09)$ & - \\
\hline Plasma VL detectable & $0.94(0.42-2.09)$ & - \\
\hline HIV duration $\geq 5$ years & $1.17(0.65-2.08)$ & - \\
\hline Past hepatitis B infection & $1.03(0.52-2.05)$ & - \\
\hline Past TB infection & $1.67(0.93-3.00)$ & - \\
\hline Past syphilis infection & 0.99 (0.56-1.74) & - \\
\hline $\begin{array}{l}\text { Any latent HIV coinfection } \\
\text { (hepatitis B, TB, syphilis) }\end{array}$ & $1.72(1.04-2.86)^{¥}$ & $1.55(0.81-2.92)$ \\
\hline
\end{tabular}

${ }^{*} p<0.10 ;{ }^{¥} p<0.05 ;{ }^{\star \star} G D S \geq 0.5$.

identification of NCI (18). Another international multisite study from the AIDS Clinical Trials Group included 62 ART-naïve Peruvian PWH (median age 33 and median educational level 12.5 years) (19). Although results were not reported for the Peruvian group, the study reported that across the entire international study, $19 \%$ of their population had mild NCI (19). Although the topic of NCI in PWH has been touched on in Peru, it has not been thoroughly studied in an objective manner. Our study is the first to study NCI in a group of middle-aged and older PWH from Peru using an objective multidomain neuropsychological battery.

When comparing our study results to similar studies based in the United States, we found that rates of NCI among PWH in Peru appear to be lower overall. For example, in a multisite study of $1,555 \mathrm{HIV}+$ adults, $52 \%$ of the total sample had NCI ( $33 \%$ of these were asymptomatic NCI, $12 \%$ mild neurocognitive disorder, and only $2 \%$ with HIV-associated dementia) (7). In another study, Latinos living in the United States had higher rates of NCI compared with non-Latino White PWH (54 vs. $42 \%$ ), and Latinos tended to perform worse in speed of information processing, working memory, recall, learning, and executive function cognitive domains compared with nonLatino White PWH (37). Latinos living in the United States are heterogeneous from differing racial groups and nationalities and tend to present with worse HIV characteristics (i.e., lower 
nadir CD4) or non-communicable comorbidities compared with non-Latino Whites, which may worsen $\operatorname{NCI}(36,37)$. In one study investigating differences in rates of NCI between US Latino and non-Latino Whites, even after adjusting for lower nadir CD4 and other HIV characteristics, Latino PWH in the United States had higher rates of NCI compared with non-Latino White PWH (OR $1.59, \mathrm{CI}=1.13-2.23, p<0.01)(37)$. Therefore, it is important to consider not only common risk factors and social determinants of health that affect Latino populations with HIV in both Latin America and the United States but also the type of neurocognitive testing norms developed for these populations.

As described earlier, prior studies on HIV-associated NCI in Latin America have demonstrated that NCI and HAND prevalence differs by country depending on the screening instrument utilized. Thus, optimization of an NCI screening instrument validated against a complete neuropsychological battery, the gold standard for diagnosis of HAND (64), is needed but remains a logistical challenge. One study from Brazil, for example, compared the IHDS scale to a brief neurocognitive battery and found that the sensitivity for detection of HAND using standardized cut points of the IHDS was $36 \%$ with a specificity of $75 \%$. The top two combinations of neuropsychological tests with the highest sensitivity compared with a gold standard neuropsychological battery were the Trail Making Test A, WAIS-3 Digit Symbol, and HVLT-R Total Recall (sensitivity 91\% and specificity 96\%) (63). The neuropsychological battery used in the present study included two of these three tests (WAIS-3 Digit Symbol and HVLT-R Total Recall) but replaced the Trail Making Test A with Color Trails Test 1 given a possible preemptive concern of lower literacy in our population. Although our study utilized similar tests to those in the Brazilian study, we did not compare our findings to a gold standard neuropsychological battery; thus, we are unable to report the sensitivity and specificity for detection of HAND of our brief neuropsychological battery. The tests utilized in our battery have been shown to have high sensitivity and specificity in other Brazilian studies with similar sociocultural norms and, thus, may be applicable in our population but may still have limitations $(19,63)$. Brazil is a Portuguese-speaking country with linguistic factors that may not be generalizable to neurocognitive testing across Spanish-speaking countries in Latin America; therefore, development of a neurocognitive battery specific to each region of Latin America is essential to capture linguistic and sociocultural factors of that region.

We found that few norms have been developed for Spanish speakers living in Peru for the majority of tests we administered; thus, we applied norms for Spanish speakers living in the United States-Mexico border with a similar demographic and sociocultural characteristics and applied norms for English speakers living in the United States when Spanish-speaker norms were unavailable for particular tests. In most prior studies on NCI, applying norms for English speakers or norms collected in Spanish-speaking countries, such as Mexico or Spain, is currently standard clinical practice (65). However, utilizing norms that are not specific to the geographic region of interest may increase the chances of either underclassifying or overclassifying NCI without appropriate demographic adjustment for that region
(66). The development of neuropsychological test norms that are representative of the diversity of Latin American populations is urgently needed. This is a key first step toward the development of validated brief cognitive screening tools that can be used in routine clinical HIV care in Lima and other Latin American cities $(8,67)$.

Risk factors for NCI in PWH are important to consider. Some studies have found that low nadir CD4 and high plasma viral load are strong predictors of NCI among PWH on ART (7). Among ART-naïve PWH, even after treatment for a mean duration of 63 months, NCI persisted among $62.8 \%$ of those with NCI prior to treatment (25); like in our study, this study found that HIV characteristics previously associated with NCI in PWH, such as absolute CD4 cell count, plasma viral load, and use of CNS-penetrating drugs, were not associated with persistent neurocognitive deficits; however, the only risk factor that contributed to persistent neurocognitive deficits after initiation of ART was lower educational levels, highlighting the importance of educational level achieved when considering NCI evaluation (25). Our sample was largely educated with $97 \%$ of the group having completed at least secondary school, higher than the mean educational level of the general population of Peru (64\% female and $75.4 \%$ male with at least some secondary schooling) (68). Two thirds of the participants in our study had some university or technical school or a post-graduate degree, likely because study recruitment took place in a specialized multidisciplinary private HIV clinic run by a non-governmental organization, and not a governmental hospital, thus attracting employed patients with higher educational levels. Given the lack of low educational levels in our sample, we did not see an association between educational levels and NCI, which may not be true of rural populations with lower educational levels in Peru. We found no other demographic variable; past medical or psychiatric history increased the risk of NCI. However, having had a latent coinfection (either hepatitis B infection, pulmonary $\mathrm{TB}$, or syphilis) was a risk factor for NCI, but these infections individually did not contribute to cognitive impairment.

Latent coinfections have been described in the literature to contribute to NCI in PWH. According to the World Health Organization Global Tuberculosis report, the incidence of TB/HIV coinfection in Peru is high, with 119 reported cases per 100,000 inhabitants in the general Peruvian population and 7.5 per 100,000 among PWH in Peru (69). One of the most commonly reported active or latent HIV coinfections to worsen NCI is TB. For example, one multinational study that included patients with HIV and active TB found that participants with active TB and HIV performed statistically significantly worse on Grooved Pegboard (motor performance) and finger tapping with the non-dominant hand compared with an HIV+ non-TB group, but sustained ART for 3 years improved cognitive function among ART-naïve PWH (70). Another study from South Africa also found that active multidrug-resistant TB coinfection was associated with significantly lower domain scores in visual attention and task switching (Trail Making Test parts A and B), visual-spatial orientation and executive function (Rey Complex Figure recall), and motor performance (Grooved Pegboard Test) (71), and a similar study found that the prevalence of HAND 
among PWH with active multidrug-resistant TB infection was $43.5 \%$ (72). The elevated risk of cognitive impairment may be mediated by higher levels of systemic inflammation among those with coinfection as was demonstrated in a study from Zambia, which reported a prevalence of NCI among 55\% of HIV $+/$ TB patients, $34 \%$ HIV + non-TB patients, and $14 \%$ of HIV-negative controls (73). Worse domain impairment among the HIV+ active TB group (compared with the HIV+ nonTB group) was noted in learning and memory (immediate and delayed recall), working memory, verbal fluency, and speed of information processing, but there were no differences in motor performance and executive function unlike prior studies from South Africa $(72,73)$. One study from southern India analyzed the effect of latent TB coinfection on NCI and found no difference in NCI prevalence between the HIV+ latent TB group and the $\mathrm{HIV}+$ non-latent TB group; however, it did find that certain inflammatory markers were higher in the HIV+ latent TB group (74). Similar to the findings of this study, our study did not find a relationship between latent $\mathrm{TB} / \mathrm{HIV}+$ coinfection on NCI, but the risk of NCI increased when several coinfections were considered simultaneously.

Syphilis is another common coinfection in $\mathrm{PWH}$, and prior syphilis infection was found to be common in our group of PWH (29.5\%) but did not independently increase risk of NCI in PWH in our study. The prevalence of syphilis in the Peruvian population is unknown, and the country does not have a government-sponsored syphilis monitoring program; however, in one study, the prevalence of syphilis in Peru was estimated to be $0.5 \%$ among men and $0.4 \%$ among women (75). Other studies have found that syphilis coinfection may worsen NCI, including one study from the CNS HIV Anti-Retroviral Therapy Effects Research (CHARTER) cohort, which found that those with prior syphilis infection had a greater number of impaired neuropsychological test domains and a worse GDS score [0.47 (0.46) vs. 0.31 (0.33) in HIV+ non-syphilis patients, $p=$ 0.03] (76). Another study demonstrated similar findings with worse neurocognitive performance among $\mathrm{PWH}$ with a prior history of syphilis infection; however, this group hypothesized that poor neurocognitive performance predisposes to more frequent acquisition of sexually transmitted infection due to risky behaviors (77). The relationship between syphilis and NCI is unknown, as one study demonstrated that neurosyphilis increases CNS inflammation but does not explain NCI (78). Our study did not find a relationship between past treated syphilis infection and NCI among PWH, but we did find that nearly one third of PWH in our study had syphilis infection, highlighting its prevalence in this population from Peru. Hepatitis B infection is less common compared with TB in Peru but has a prevalence of 0.75 per 100,000 inhabitants (79). Very few studies have investigated the effect of past hepatitis B infection and HIV on NCI as most studies have focused on HIV/HCV coinfection. However, in our study, hepatitis $\mathrm{C}$ infection was very rare, and past hepatitis $B$ infection was much more common. Only one study found an increase in impairment of verbal learning and memory among a cohort of HCV and HBV patients without HIV compared to heathy controls (80). Our study demonstrated an increased risk of past infection with pulmonary $\mathrm{TB}$, syphilis, or hepatitis B infection on NCI in unadjusted analyses, but not in adjusted analyses, highlighting the importance of management and treatment of coinfections more prevalent in Latin America to prevent NCI among PWH.

Depression risk is known to be greater in older $\mathrm{PWH}$, yet few studies have reported on depression prevalence among middle-aged and older adult PWH in Latin America, particularly on its effect on NCI (81). The PHQ-9 has been utilized in Latin American populations, including in rural areas of Mexico, suggesting that the internal consistency of the PHQ-9 was good overall and in subgroups of low literacy levels, gender, and age (50). The PHQ-9 has also been validated for use in Peru (49), and studies suggest that those of lower socioeconomic status or from rural areas had lower rates of depression (82). One study from Latin America of 412 Brazilian PWH utilized the Beck Depression Inventory (BDI) for depression screening and found that a BDI score between 13 and 19 points was associated with symptomatic HAND (mild neurocognitive disorder and HIV-associated dementia) (16). Another study of older Brazilian PWH aged $\geq 50$ years found that the frequency of mild neurocognitive disorder using the MMSE was $36.5 \%$ and that depressive symptoms were present in $34.6 \%$ of participants using the BDI-II (59). This study found that depression was a risk factor for greater functional impairment (59), yet our study results do not suggest a relationship between higher PHQ-9 score and NCI among PWH, likely because we did not identify persons with symptomatic HAND or functional impairment. A unified approach to identifying those older $\mathrm{PWH}$ at greatest risk for depression is needed by applying culturally appropriate depression screening tools and considering depression screening when evaluating for NCI in older PWH.

Our study has limitations. Firstly, this was a cross-sectional study capturing NCI at one isolated time point during the course of HIV illness and did not capture longitudinal data on cognitive decline. Thus, no inferences can be made on the risk of progressing from asymptomatic NCI to symptomatic forms of HAND (mild neurocognitive disorder or HIV-associated dementia). Second, there are no neuropsychological test norms specific to Lima, Peru; thus, norms for Spanish speakers with similar sociocultural norms were utilized when available (NPNUMBRS), and English-speaking norms were used for those in which NP-NUMBRS norms were unavailable. Although we adjusted for demographic variables (age, sex, and educational level), without neuropsychological test norms specific to the region of study, NCI may be underestimated or overestimated. Lastly, it is important to note that this study and the neuropsychological battery utilized may not be generalizable to populations of lower literacy or lower educational levels, particularly in rural populations. Participants in our study had a mean educational level of $14 \pm 3$ years, with the large majority (97\%) having completed at least secondary school and twothirds having had some university or technical school. This figure is much greater than the proportion of Peruvians in the general population across all of Peru with up to secondary school completed (64\% female and $75.4 \%$ male) (68). Our results may be generalizable to certain regions of Lima with higher educational levels comparable to our population, but they may 
not be generalizable to rural populations or other metropolitan areas of Peru and other LAC. Illiteracy and low educational levels are common across Latin America, including Peru, where the illiteracy level is $6 \%$ (83), and higher among older adults living in rural areas of Peru compared with urban settings (41.6\% rural vs. $12.3 \%$ urban), thus limiting the external validity of our results to low-literacy or illiterate populations in Peru and elsewhere in Latin America (84). Lastly, the sample size was not large $(N=144)$, thus limiting conclusions that may be made regarding risk factors of NCI. However, a post-hoc power calculation was conducted to determine the power of this study to detect $\mathrm{TB}$ as a risk factor of interest for cognitive impairment among $\mathrm{PWH}$. TB was selected as a risk factor for NCI in the post-hoc power calculation because of evidence from previous studies that it is a risk factor for cognitive impairment $(71,74)$; it is a common exposure in Peru (85) and is commonly associated with HIV (86). Given that our secondary aim was to explore risk factors related to NCI, we calculated the power to detect a statistically significant difference in the exposure (TB) when comparing its frequency among those with and without NCI. Given that 21 participants had a history of TB, our study had a power $>80 \%$ for a PR of 3.35 or higher.

Despite these limitations, our study is the first to report the rates of NCI among a group of middle-aged and older adult Peruvians with HIV living in the capital city of Lima, utilizing a multidomain objective neurocognitive battery. We have highlighted the need to validate a brief cognitive screening tool that may be generalizable and applicable across the wide spectrum of educational and literacy levels, in order to enhance the external validity of the tool. Neuropsychological test norms specific to Lima, Peru, that account for the sociocultural context and demographics of urban Peru are also key in being able to properly define the rate of NCI seen in an aging HIV population. There is a need for long-term longitudinal data that characterizes whether people with NCI without functional impairment may progress to symptomatic forms with functional impairment and whether cognitive decline should be a concern as PWH age in Peru and throughout Latin America. Demonstrating these aspects of HIV-associated NCI across all of Peru, including in urban and rural areas across the spectrum of educational levels, will allow for the creation of new therapeutic targets and management strategies for HAND in LMICs.

\section{DATA AVAILABILITY STATEMENT}

The raw data supporting the conclusions of this article will be made available by the authors, without undue reservation.

\section{ETHICS STATEMENT}

The studies involving human participants were reviewed and approved by Universidad Peruana Cayetano Heredia (Lima,
Peru). The patients/participants provided their written informed consent to participate in this study.

\section{AUTHOR CONTRIBUTIONS}

MD study concept and design, data collection, performance of statistical analyses, interpretation of analyses, and drafting of manuscript. MZ study concept and design, data collection, interpretation of analyses, and drafting of manuscript. PS study concept and design, analysis and interpretation, and drafting of manuscript. MS data collection, interpretation of analyses, and drafting of manuscript. DF data management and analyses and drafting of manuscript. MM and MC study concept and design and critical revision of the manuscript for important intellectual content. CC supervised statistical analyses, interpretation of analyses, and critical revision of manuscript. RE and SL study concept and design, interpretation of analyses, and critical revision of the manuscript for important intellectual content. PG study concept and design, interpretation of analyses, drafting of the manuscript, and critical revision of the manuscript for important intellectual content. All authors contributed to the article and approved the submitted version.

\section{FUNDING}

MD serves as a Fogarty Global Health Trainee and was supported by the Fogarty International Center at the NIH under grant number D43TW009343 and was also supported by the Alzheimer's Disease Resource Center for advancing Minority Aging Research at the University of California, San Diego (P30AG059299, National Institute on Aging). This work was supported by grants from the National Institutes of Health (the HIV Neurobehavioral Research Center (HNRC): P30MH62512, R01MH57266, K23MH105297, P30AG059299, T32MH019934, and P01DA012065). The HIV Neurobehavioral Research Center (HNRC) was supported by center award P30MH062512 from the National Institute of Mental Health.

\section{ACKNOWLEDGMENTS}

We would like to thank the nursing staff and administrative staff at Via Libre HIV clinic. We would also like to thank Dr. Robinson Cabello and Mr. Manuel Rouillon, center directors of Via Libre HIV clinic. We would like to thank the research assistants who supported this work, including Marcela Gil-Zacarias, Dr. Maria Fatima Sanes Guevara, Dr. Alex Miguel Vargas Romero, and Ms. Adriana Naranjo Garcia.

\section{SUPPLEMENTARY MATERIAL}

The Supplementary Material for this article can be found online at: https://www.frontiersin.org/articles/10.3389/fneur. 2021.629257/full\#supplementary-material 


\section{REFERENCES}

1. Custodio N, Wheelock A, Thumala D, Slachevsky A. Dementia in latin america: epidemiological evidence and implications for public policy. Front Aging Neurosci. (2017) 9:221. doi: 10.3389/fnagi.2017.00221

2. Cardoso SW, Torres TS, Santini-Oliveira M, Marins LMS, Veloso VG, Grinsztejn B. Aging with HIV: a practical review. Braz J InfectDis. (2013) 17:464-79. doi: 10.1016/j.bjid.2012.11.007

3. UNAIDS. HIV and Aging - A Special Supplement to the UNAIDS Report on the Global AIDS Epidemic 2013 - World. ReliefWeb (2013). Available online at: https://reliefweb.int/report/world/hiv-and-aging-specialsupplement-unaids-report-global-aids-epidemic-2013 (accessed May 30, 2020).

4. Sousa RM, Ferri CP, Acosta D, Guerra M, Huang Y, Jacob K, et al. The contribution of chronic diseases to the prevalence of dependence among older people in Latin America, China and India: a 10/66 dementia research group population-based survey. BMC Geriatrics. (2010) 10:53. doi: 10.1186/1471-2318-10-53

5. Sheppard DP, Iudicello JE, Bondi MW, Doyle KL, Morgan EE, Massman PJ, et al. Elevated rates of mild cognitive impairment in HIV disease. J Neurovirol. (2015) 21:576-84. doi: 10.1007/s13365-015-0366-7

6. Heaton RK, Franklin DR, Ellis RJ, McCutchan JA, Letendre SL, Leblanc $\mathrm{S}$, et al. HIV-associated neurocognitive disorders before and during the era of combination antiretroviral therapy: differences in rates, nature, and predictors. J Neurovirol. (2011) 17:3-16. doi: 10.1007/s13365-010-0006-1

7. Heaton RK, Clifford DB, Franklin DR, Woods SP, Ake C, Vaida F, et al. HIV-associated neurocognitive disorders persist in the era of potent antiretroviral therapy: CHARTER study. Neurology. (2010) 75:208796. doi: 10.1212/WNL.0b013e318200d727

8. Saloner R, Cysique LA. HIV-associated neurocognitive disorders: a global perspective. J Int Neuropsychol Soc. (2017) 23:8609. doi: $10.1017 / S 1355617717001102$

9. Antinori A, Arendt G, Becker JT, Brew BJ, Byrd DA, Cherner M, et al. Updated research nosology for HIV-associated neurocognitive disorders. Neurology. (2007) 69:1789-99. doi: 10.1212/01.WNL.0000287431.88658.8b

10. Ellis RJ, Deutsch R, Heaton RK, Marcotte TD, McCutchan JA, Nelson JA, et al. Neurocognitive impairment is an independent risk factor for death in HIV infection. San Diego HIV neurobehavioral research center group. Arch Neurol. (1997) 54:416-24. doi: 10.1001/archneur.1997.00550160054016

11. McArthur JC. HIV dementia: an evolving disease. J Neuroimmunol. (2004) 157:3-10. doi: 10.1016/j.jneuroim.2004.08.042

12. Sacktor N, Saylor D, Nakigozi G, Nakasujja N, Robertson K, Grabowski MK, et al. Effect of HIV subtype and antiretroviral therapy on HIV-associated neurocognitive disorder stage in rakai, Uganda. J Acquir Immune Defic Syndr. (2019) 81:216-23. doi: 10.1097/QAI.0000000000001992

13. Instituto Nacional de Estadistica e Informatica. Peru Final Version of OECD Review of Official Statistics and Statistical System. (2017). Available online at: https://www.inei.gob.pe/media/ocde/English.pdf

14. Tozzi V, Balestra P, Lorenzini P, Bellagamba R, Galgani S, Corpolongo A, et al. Prevalence and risk factors for human immunodeficiency virus-associated neurocognitive impairment, 1996 to 2002: results from an urban observational cohort. J Neurovirol. (2005) 11:265-73. doi: 10.1080/13550280590952790

15. Robertson K, Bayon C, Molina JM, McNamara P, Resch C, Muñoz-Moreno JA, et al. Screening for neurocognitive impairment, depression, and anxiety in HIV-infected patients in Western Europe and Canada. AIDS Care. (2014) 26:1555-61. doi: 10.1080/09540121.2014.936813

16. Gascón MRP, Vidal JE, Mazzaro YM, Smid J, Nascimento RM, Garcia C, et al. Neuropsychological assessment of 412 HIV-infected individuals in São Paulo, Brazil. AIDS Patient Care STDS. (2018) 32:1-8. doi: 10.1089/apc.2017.0202

17. Wright EJ, Grund B, Cysique LA, Robertson K, Brew BJ, Collins G, et al. Factors associated with neurocognitive test performance at baseline: a substudy of the INSIGHT strategic timing of antiretroviral treatment (START) trial. HIV Med. (2015) 16:97-108. doi: 10.1111/hiv.12238

18. Weikum D, Shrestha R, Ferro EG, Vagenas P, Copenhaver, Spudich $\mathrm{S}$, et al. An explanatory factor analysis of a brief self-report scale to detect neurocognitive impairment among HIV-positive men who have sex with men and transgender women in Peru. AIDS Care. (2017) 29:1297301. doi: $10.1080 / 09540121.2017 .1322681$
19. Robertson K, Jiang H, Kumwenda J, Supparatpinyo K, Evans S, Campbell T, et al. Improved neuropsychological and neurological functioning across three antiretroviral regimens in diverse resource-limited settings: AIDS clinical trials group study a5199, the international neurological study. Clin Infect Dis. (2012) 55:868-76. doi: 10.1093/cid/cis507

20. Centro Nacional de Epidemiologia, Prevencion y Control de Enfermedades. Situación epidemiológica del VIH-Sida en el Perú. (2018).Available online at: https://www.dge.gob.pe/portal/index.php?option=com_content\&view= article\&id $=656$ (accessed June 5, 2020).

21. ONUSIDA. Perú - Country Factsheets. Available online at: https://www. unaids.org/es/regionscountries/countries/peru (accessed June 5, 2020).

22. Patel S, Parikh NU, Aalinkeel R, Reynolds JL, Dmello R, Schwartz SA, et al. United States National trends in mortality, length of stay (LOS) and associated costs of cognitive impairment in HIV population from 2005 to (2014). AIDS Behav. (2018) 22:3198-208. doi: 10.1007/s10461-018-2128-z

23. Alzheimer's Association. Can Alzheimer's Disease Be Prevented? (2020). Available online at: https://www.alz.org/alzheimers-dementia/research_ progress/prevention (accessed October 21, 2020).

24. Carey CL, Woods SP, Rippeth JD, Gonzalez R, Moore DJ, Marcotte $\mathrm{TD}$, et al. Initial validation of a screening battery for the detection of HIV-associated cognitive impairment. Clin Neuropsychol. (2004) 18:23448. doi: 10.1080/13854040490501448

25. Tozzi V, Balestra P, Bellagamba R, Corpolongo A, Salvatori MF, ViscoComandini U, et al. Persistence of neuropsychologic deficits despite longterm highly active antiretroviral therapy in patients with HIV-related neurocognitive impairment: prevalence and risk factors. J Acquir Immune Defic Syndr. (2007) 45:174-82. doi: 10.1097/QAI.0b013e318042elee

26. de Almeida SM, Ribeiro CE, de Pereira AP, Badiee J, Cherner M, Smith D, et al. Neurocognitive impairment in HIV-1 clade C- versus B-infected individuals in Southern Brazil. J Neurovirol. (2013) 19:5506. doi: 10.1007/s13365-013-0215-5

27. D’Elia LF, Satz P., Uchiyama CL, White T. Color trails test. PAR. (1996). https://www.parinc.com/Products/Pkey/77 (accessed October 21, 2020).

28. Merker B, Podell K. Grooved pegboard test. In: Kreutzer JS, DeLuca J, Caplan B, editors. Encyclopedia of Clinical Neuropsychology. New York, NY: Springer. (2011). doi: 10.1007/978-0-387-79948-3_187

29. Belkonen S. 2011 Hopkins verbal learning test. In: Kreutzer JS, DeLuca J, Caplan B, editors. Encyclopedia of Clinical Neuropsychology. New York, NY: Springer. doi: 10.1007/978-0-387-79948-3_1127

30. Possin KL, Laluz VR, Alcatar OZ, Miller BL, Kramer JH. Distinct neuroanatomical substracts and cognitive mechanisms of figure copy performance in Alzheimer's disease and behavioral fronto-temporal dementia. Neuropsychologia. (2011) 49:438. doi: 10.1016/j.neuropsychologia.2010.10.026

31. WAIS-III. In: Kreutzer JS, DeLuca J, Caplan B, editors. Encyclopedia of Clinical Neuropsychology. New York, NY: Springer (2011).

32. Pena-Casanova J, Quinones-Ubeda S, Gramunt-Fombuena N, QuintanaAparicio M, Aguilar M, Badenes D, et al. Spanish multicenter normative studies (NEURONORMA Project): norms for verbal fluency tests. Arch Clin Neuropsychol. (2009) 24:395-411. doi: 10.1093/arclin/acp042

33. Pontón MO, Satz P, Herrera L, Ortiz F, Urrutia CP, Young R, et al. Normative data stratified by age and education for the neuropsychological screening battery for hispanics (NeSBHIS): initial report. J Int Neuropsychol Soc. (1996) 2:96-104. doi: 10.1017/S1355617700000941

34. Tsoy E, Possin KL, Thompson N, Patel K, Garrigues SK, Maravilla I, et al. Selfadministered cognitive testing by older adults at-risk for cognitive decline. $J$ Prev Alzheimer's Dis. (2020) 7:283-7. doi: 10.14283/jpad.2020.25

35. Mindt MR, Cherner M, Marcotte TD, Moore DJ, Bentley H, Esquivel M, et al. The functional impact of HIV-associated neuropsychological impairment in spanish-speaking adults: a pilot study. J Clin Exp Neuropsychol. (2003) 25:122-32. doi: 10.1076/jcen.25.1.122.13634

36. Kamalyan L, Hussain MA, Diaz MM, Umlauf A, Franklin DR, Cherner M, et al. Neurocognitive impairment in Spanish-speaking Latinos living with HIV in the US: Application of the neuropsychological norms for the US-Mexico border region in Spanish (NP-NUMBRS). Clin Neuropsychol. (2019) 35:43352. doi: 10.1080/13854046.2019.1701084

37. Marquine MJ, Heaton A, Johnson N, Rivera-Mindt M, Cherner M, Bloss $\mathrm{C}$, et al. Differences in neurocognitive impairment among HIV-INFECTED 
LATINOS IN THE United States. J Int Neuropsychol Soc. (2018) 24:16375. doi: 10.1017/S1355617717000832

38. Marquine MJ, Morlett Paredes A, Madriaga C, Blumstein Y, Umlauf A, Kamalyan L, et al. Demographically-adjusted norms for selected tests of verbal fluency: results from the neuropsychological norms for the US-Mexico Border Region in Spanish (NP-NUMBRS) project. Clin Neuropsychol. (2020) 35:269-92. doi: 10.1080/13854046.2020.1762931

39. Diaz-Santos M, Suarez P, Marquine MJ, Umlauf A, Rivera-Mindt M, Artiola I Fortuny L, et al. Updated demographically adjusted norms for the brief visuospatial memory test-revised and hopkins verbal learning test-revised in monolingual spanish speakers from the United States - Mexico Border region. Arch Clin Neuropsychol. (2019) 34:1250. doi: 10.1093/arclin/acz029.17

40. Heaton A, Gooding A, Cherner M, Umlauf A, Franklin DR, Rivera-Mindt M, et al. Demographically-adjusted norms for the grooved pegboard and finger tapping tests in Spanish-speaking adults: results from the neuropsychological norms for the U.S.-Mexico Border Region in Spanish (NP-NUMBRS) project. Clin Neuropsychol. (2020) 35:396-418. doi: 10.1080/13854046.2020.1713400

41. Carey CL, Woods SP, Gonzalez R, Conover E, Marcotte TD, Grant I, et al. Predictive validity of global deficit scores in detecting neuropsychological impairment in HIV INFECTION. J Clin Exp Neuropsychol. (2004) 26:30719. doi: $10.1080 / 13803390490510031$

42. Heaton RK, Miller SW, Taylor MJ, Grant I. Revised Comprehensive Norms for an Expanded Halstead-Reitan Battery: Demographically Adjusted Neuropsychological Norms for African American and Caucasian Adults. Lutz, FL: Psychological Assessment Resources, Inc. (2004).

43. Pfeffer RI, Kurosaki TT, Harrah CHJ, Chance JM, Bates D, Detels R, et al. A survey diagnostic tool for senile dementia. Am J Epidemiol. (1981) 114:51527. doi: 10.1093/oxfordjournals.aje.a113217

44. Herrera P MS, Saldías P, Testa N. [Validation of a brief screening test to assess functional capacity in Chilean older people]. Rev Med Chil. (2014) 142:1128-35. doi: 10.4067/S0034-98872014000900006

45. Quiroga L P, Albala B C, Klaasen P G. Validación de un test de tamizaje para el diagnóstico de demencia asociada a edad, en Chile. Rev méd Chile. (2004) 132:467-78. doi: 10.4067/S0034-98872004000400009

46. Kroenke K, Spitzer RL, Williams JBW. The PHQ-9: validity of a brief depression severity measure. J Gen Intern Med. (2001) 16:60613. doi: 10.1046/j.1525-1497.2001.016009606.x

47. Levis B, Benedetti A, Thombs BD. Accuracy of patient health Questionnaire-9 (PHQ-9) for screening to detect major depression: individual participant data meta-analysis. BMJ. (2019) 365:11476. doi: 10.1136/bmj.11476

48. Spitzer RL. Validation and utility of a self-report version of PRIME-MDThe PHQ primary care study. JAMA. (1999) 282:1737. doi: 10.1001/jama.282.18.1737

49. Calderón M, Gálvez-Buccollini JA, Cueva G, Ordoñez C, Bromley C, Fiestas F. Validación de la versión peruana del PHQ-9 para el diagnóstico de depresión. Rev Peru Med Exp Salud Publica. (2012) 29:57879. doi: 10.1590/S1726-46342012000400027

50. Arrieta J, Aguerrebere M, Raviola G, Flores H, Elliott P, Espinosa A, et al. Validity and utility of the patient health questionnaire (PHQ)-2 and PHQ-9 for screening and diagnosis of depression in rural Chiapas, Mexico: a crosssectional study: PHQ-9 validity for depression diagnosis. J Clin Psychol. (2017) 73:1076-90. doi: 10.1002/jclp.22390

51. Muñoz-Navarro R, Cano-Vindel A, Medrano LA, Schmitz F, Ruiz-Rodriguez P, Abellan-Maeso C, et al. Utility of the PHQ-9 to identify major depressive disorder in adult patients in Spanish primary care centres. BMC Psychiatry. (2017) 17:291. doi: 10.1186/s12888-017-1450-8

52. Wulsin L, Somoza E, Heck J. The feasibility of using the Spanish PHQ-9 to screen for depression in primary care in honduras. Prim Care Companion $J$ Clin Psychiatry. (2002) 4:191-5. doi: 10.4088/PCC.v04n0504

53. Cholera R, Gaynes BN, Pence BW, Bassett J, Qangule N, Macphail C, et al. Validity of the patient health questionnaire- 9 to screen for depression in a high-HIV burden primary healthcare clinic in Johannesburg, South Africa. $J$ Affect Disord. (2014) 167:160-6. doi: 10.1016/j.jad.2014.06.003

54. Sereia AL, Junior MS, Domiciano TP, Shimauti E, Pupulin ART. Mini mental state examination and evaluation of factors associated with cognitive decline in HIV/AIDS-infected people. Acta Sci Health Sci. (2012) 34:1938. doi: 10.4025/actascihealthsci.v34i2.12687
55. Araujo ML, Duarte W, Oliveira ACP de, Polo MR, Marcondes LA, Alves $\mathrm{RM}$, et al. Is the telomere length associated with neurocognitive disabilities in HIV-1-infected subjects? Revista do Instituto de Medicina Tropical de Sáo Paulo. (2018). Available online at: http://www.scielo.br/scielo.php?script=sci_ arttext\&pid=S0036-46652018005000207\&lng=en\&nrm=iso\&tlng=enhttp:// ovidsp.ovid.com/ovidweb.cgi?T=JS\&CSC=Y\&NEWS=N\&PAGE=fulltext\& $\mathrm{D}=$ cagh\&AN=20193122783http://wa4py6yj8t.search.serialssolutions.com/? url_ver=Z39.88-2004

56. Pinheiro CAT, Mattos Souza LD de, Motta JV dos S, Kelbert EF, Martins CSR, Souza MS, et al. Aging, neurocognitive impairment and adherence to antiretroviral therapy in human immunodeficiency virus-infected individuals. Braz J Infect Dis. (2016) 20:599-604. doi: 10.1016/j.bjid.2016.09.006

57. Pinheiro CAT, Souza LDM, Motta JVS, Kelbert EF, Souza MS, Martins CSR, et al. Depression and diagnosis of neurocognitive impairment in HIV-positive patients. Braz J Med Biol Res. (2016) 49:e5344. doi: 10.1590/1414-431x20165344

58. Troncoso FT, Conterno L de O. Prevalence of neurocognitive disorders and depression in a Brazilian HIV population. Rev Soc Bras Med Trop. (2015) 48:390-8. doi: 10.1590/0037-8682-0034-2015

59. Filho SMMF, de Melo HRL. Frequency and risk factors for HIVassociated neurocognitive disorder and depression in older individuals with HIV in northeastern Brazil. Int Psychogeriatr. (2012) 24:164855. doi: $10.1017 /$ S1041610212000944

60. Robertson K, Kumwenda J, Supparatpinyo K, Jiang JH, Evans S, Campbell $\mathrm{TB}$, et al. A multinational study of neurological performance in antiretroviral therapy-naïve HIV-1-infected persons in diverse resource-constrained settings. J Neurovirol. (2011) 17:438-47. doi: 10.1007/s13365-011-0044-3

61. Zamudio-Rodriguez A, Belaunzaran-Zamudio PF, Sierra-Madero JG, CuellarRodriguez J, Crabtree-Ramirez BE, Alcala-Zermeno JL, et al. Association between frailty and HIV-associated neurodegenerative disorders among older adults living with HIV. AIDS Res Hum Retroviruses. (2018) 34:44955. doi: 10.1089/aid.2017.0100

62. Folstein MF, Folstein SE, McHugh PR. "Mini-mental state". A practical method for grading the cognitive state of patients for the clinician. J Psychiatr Res. (1975) 12:189-98. doi: 10.1016/0022-3956(75)90026-6

63. de Almeida M, Kamat R, Cherner M, Umlauf A, Ribeiro CE, de Pereira AP, et al. Improving detection of HIV-associated cognitive impairment: comparison of the international HIV dementia scale and a brief screening battery. J Acquir Immune Defic Syndr. (2017) 74:7. doi: 10.1097/QAI.0000000000001224

64. Carroll A, Brew B. HIV-associated neurocognitive disorders: recent advances in pathogenesis, biomarkers, and treatment. F1000Res. (2017) 6:312. doi: 10.12688/f1000research.10651.1

65. Morlett Paredes A, Gooding A, Artiola i Fortuny L, Rivera-Mindt M, Suarez P, Scott TM, et al. The state of neuropsychological test norms for Spanish-speaking adults in the United States. Clin Neuropsychol. (2020) 35:236-52. doi: 10.1080/13854046.2020.172 9866

66. Arango-Lasprilla JC. Commonly used neuropsychological tests for spanish speakers: normative data from Latin America. NeuroRehabilitation. (2015) 37:489-91. doi: 10.3233/NRE-151276

67. The Mind Exchange Working Group, Antinori A, Arendt G, Grant I, Letendre S, Muñoz-Moreno JA, et al. Assessment, diagnosis, and treatment of HIVassociated neurocognitive disorder: a consensus report of the mind exchange program. Clin Infect Dis. (2013) 56:1004-17. doi: 10.1093/cid/cis975

68. INEI, Instituto Nacional de Estadisticas e Informatica. PERÚ: Indicadores del Índice de Desigualdad de Género referidos a participación política, empleo y educación, según departamento 2018 (2018). Available online at: https://www.inei.gob.pe/estadisticas/indice-tematico/brechas-de-genero7913/ (accessed October 29, 2020).

69. World Health Organization. World Health Organization, Global Tuberculosis Report. Peru (2020). https://www.who.int/teams/global-tuberculosisprogramme/global-tuberculosis-report- 2020 (accessed October 30, 2020).

70. Robertson KR, Oladeji B, Jiang H, Kumwenda J, Supparatpinyo K, Campbell TB, et al. Human immunodeficiency virus type 1 and tuberculosis coinfection in multinational, resource-limited settings: increased neurological dysfunction. Clin Infect Dis. (2019) 68:1739-46. doi: 10.1093/cid/ciy718 
71. Ramlall S, Lessells RJ, Naidu T, Mthembu SS, Padayatchi N, Burns JK, et al. Neurocognitive functioning in MDR-TB patients with and without HIV in KwaZulu-Natal, South Africa. Trop Med Int Health. (2020) 25:91927. doi: $10.1111 /$ tmi.13444

72. Tomita A, Ramlall S, Naidu T, Mthembu SS, Padayatchi N, Burns JK. Neurocognitive impairment risk among individuals with multiple drug-resistant tuberculosis and human immunodeficiency virus coinfection: implications for systematic linkage to and retention of care in tuberculosis/human immunodeficiency virus treatment. J Nerv Ment Dis. (2019) 207:307-10. doi: 10.1097/NMD.0000000000000962

73. Hestad KA, Chinyama J, Anitha MJ, Ngoma NS, McCutchan JA, Franklin DR Jr, et al. Cognitive impairment in zambians with HIV infection and pulmonary tuberculosis. J Acquir Immune Defic Syndr. (2019) 80:1107. doi: 10.1097/QAI.0000000000001880

74. LaVergne S, Umlauf A, McCutchan A, Heaton R, Benson C, Kumarasamy N, et al. Impact of latent tuberculosis infection on neurocognitive functioning and inflammation in HIV-infected and Uninfected South Indians. J Acquir Immune Defic Syndr. (2020) 84:430-6. doi: 10.1097/QAI.0000000000002368

75. Cárcamo CP, Campos PE, García PJ, Hughes JP, Garnett GP, Holmes KK. Prevalences of sexually transmitted infections in young adults and female sex workers in Peru: a national population-based survey. Lancet Infect Dis. (2012) 12:765-73. doi: 10.1016/S1473-3099(12)70144-5

76. Marra CM, Deutsch R, Collier AC, Morgello S, Letendre S, Gelman $B$, et al. Neurocognitive impairment in HIV-infected individuals with previous syphilis. Int J STD AIDS. (2013) 24:351-5. doi: 10.1177/0956462412 472827

77. Wallace MR, Heaton RK, McCutchan JA, Malone JL, Velin R, Nelson J, et al. Neurocognitive impairment in human immunodeficiency virus infection is correlated with sexually transmitted disease history. Sex Transm Dis. (1997) 24:398-401. doi: 10.1097/00007435-199708000-00003

78. Ho EL, Maxwell CL, Dunaway SB, Sahi SK, Tantalo LC, Lukehart SA, et al. Neurosyphilis increases human immunodeficiency virus (HIV)-associated central nervous system inflammation but does not explain cognitive impairment in HIV-infected individuals with syphilis. Clin Infect Dis. (2017) 65:943-8. doi: 10.1093/cid/cix473

79. Peru Ministerio de Salud. Centro Nacional de Epidemiologia, Prevención y Control de Enfermedades - MINSA (*) Hasta la SE 5 del 2018 (2018). Available online at: http://www.dge.gob.pe/portal/docs/vigilancia/sala/2018/ SE05/hepatitisb.pdf (accessed October 30, 2020).
80. Karaivazoglou K, Assimakopoulos K, Thomopoulos K, Theocharis G, Messinis L, Sakellaropoulos G, et al. Neuropsychological function in Greek patients with chronic hepatitis C. Liver Int. (2007) 27:798805. doi: 10.1111/j.1478-3231.2007.01486.x

81. Carmo Filho A do, Fakoury MK, Eyer-Silva W de A, Neves-Motta R, Kalil RS, Ferry FR de A. Factors associated with a diagnosis of major depression among HIV-infected elderly patients. Rev Soc Brasil Med Trop. (2013) 46:3524. doi: 10.1590/0037-8682-1228-2013

82. Villarreal-Zegarra D, Cabrera-Alva M, Carrillo-Larco RM, BernabeOrtiz A. Trends in the prevalence and treatment of depressive symptoms in Peru: a population-based study. BMJ Open. (2020) 10:e036777. doi: 10.1136/bmjopen-2020-036777

83. The World Bank. The World Bank. Literacy Rate, Adult Total (\% of people ages 15 and above). UNESCO Institute for Statistics (uis.unesco.org) (2018). https://data.worldbank.org/indicator/SE.ADT.LITR.ZS?locations= ZJ-PE

84. Instituto Nacional de Estadística e Informática. Perú: Crecimiento y Distribución de la Población 2017. In: Aponte FC, editor. Censos Nacionales 2017: XII de Población y VII de Vivienda. Lima: PRIMEROS RESULTADOS (2018). p. 15-6.

85. Brooks-Pollock E, Becerra MC, Goldstein E, Cohen T, Murray MB. Epidemiologic inference from the distribution of tuberculosis cases in households in Lima, Peru. J Infect Dis. (2011) 203:15829. doi: 10.1093/infdis/jir162

86. Mollel EW, Maokola W, Todd J, Msuya SE, Mahande MJ. Incidence rates for tuberculosis among HIV infected patients in Northern Tanzania. Front Public Health. (2019) 7:306. doi: 10.3389/fpubh.2019.00306

Conflict of Interest: The authors declare that the research was conducted in the absence of any commercial or financial relationships that could be construed as a potential conflict of interest.

Copyright (C) 2021 Diaz, Zacarías, Sotolongo, Sanes, Franklin, Marquine, Cherner, Cárcamo, Ellis, Lanata and García. This is an open-access article distributed under the terms of the Creative Commons Attribution License (CC BY). The use, distribution or reproduction in other forums is permitted, provided the original author(s) and the copyright owner(s) are credited and that the original publication in this journal is cited, in accordance with accepted academic practice. No use, distribution or reproduction is permitted which does not comply with these terms. 